\title{
Effect of Soil Temperature and Plant Age at Time of Inoculation on Progress of Root Rot and Foliar Symptoms of Soybean Sudden Death Syndrome
}

\author{
C. C. Gongora-Canul and L. F. S. Leandro, Department of Plant Pathology, Iowa State University, Ames 50010
}

\begin{abstract}
Gongora-Canul, C. C., and Leandro, L. F. S. 2011. Effect of soil temperature and plant age at time of inoculation on progress of root rot and foliar symptoms of soybean sudden death syndrome. Plant Dis. 95:436-440.

Sudden death syndrome (SDS) of soybean is favored by planting in cool soil but epidemics can be severe even when planting occurs later in the season into warmer soil. Our objective was to determine how soil temperature affects susceptibility of plants exposed to Fusarium virguliforme at different ages. Soybean plants were grown in rhizotrons in water baths at 17,23 , and $29^{\circ} \mathrm{C}$. Subsets of plants were inoculated 0 , 3,7 , and 13 days after planting (DAP) by drenching soil with a conidial suspension. Root rot developed in all inoculated plants but severity decreased with increasing temperature and plant age at inoculation. Severity of foliar symptoms also decreased with increasing plant age.

Whereas plants inoculated 0 DAP developed severe foliar symptoms at all temperatures, plants inoculated 3 and 7 DAP developed symptoms only at 17 and $23^{\circ} \mathrm{C}$, and those inoculated 13 DAP never developed foliar symptoms at any temperature. Root length at inoculation was negatively correlated with disease severity. Our findings suggest that roots are most susceptible to infection during the first days after seed germination and that accelerated root growth in warmer temperatures reduces susceptibility to root infection conducive to foliar symptoms. However, soil temperature may not affect infections that occur as soon as seeds germinate.
\end{abstract}

Sudden death syndrome (SDS), caused by the soilborne fungus Fusarium virguliforme (O'Donnell \& T. Aoki) (1), is an economically important disease of soybean (Glycine $\max$ (L.) Merr.) in the United States (33). Infection by $F$. virguliforme causes root rot as well as chlorosis and necrosis of leaves due to the translocation of pathogen toxins from the roots (11). Colonization of the xylem by $F$. virguliforme is thought to be needed for development of foliar symptoms (18), and it is possible for plants to show root rot but not foliar symptoms if fungal colonization is restricted to the cortical tissue $(7,18)$. Severity of SDS is highly dependent on environmental conditions, especially temperature and moisture (26-28). The disease is favored by cool and wet soil at the beginning of the growing season and high soil moisture throughout the growing season $(9,15,23,26,32)$. Controlled environment studies (26) showed that soil temperature of $15^{\circ} \mathrm{C}$ was optimal for root rot, whereas temperatures of 22 to $24^{\circ} \mathrm{C}$ were optimal for expression of foliar symptoms.

In an earlier study (6), plant age at inoculation had a major impact on SDS severity. Soybean plants inoculated from seed up through V5 (fifth trifoliate) developed root rot but foliar symptoms were observed only on those plants inoculated as seed. Absence of foliar symptoms in older plants was associated with limited colonization of the xylem, suggesting that roots become less susceptible to SDS as they mature, possibly due to lack of toxin translocation to the leaves (18).

Previous research has shown that plant roots can become more resistant to pathogen invasion as they mature $(8,12,29)$, partly due to accumulation of suberin and lignin $(21,30)$. Therefore, growing conditions that favor plant development may reduce susceptibility to disease, as was reported for black root rot of cotton, caused by Thielaviopsis basicola (22,31). With SDS, planting early in the growing season in cool and wet soil increases the risk of disease $(9,32)$, suggesting that young roots growing in cool soils are most susceptible to infection by $F$. virguliforme. Nevertheless, SDS can

Corresponding author: L. F. S. Leandro, E-mail: 1leandro@iastate.edu

Accepted for publication 23 November 2010.

doi:10.1094/PDIS-07-10-0489

(C) 2011 The American Phytopathological Society still develop where soybean crops are planted later in the season into warmer soil $(5,9,32)$. The interaction between plant age and temperature in the SDS pathosystem and its importance in early root infection stages have not been well characterized. The hypothesis of this study was that soybean plants grown in warmer soil temperatures would be susceptible to root infection and subsequent development of foliar symptoms for a shorter period of time than plants grown in cool soil due to the faster root growth rate. The objective of the study was to characterize the interactive effect of soil temperature and plant age at inoculation on progress of SDS root rot and foliar symptom expression.

\section{Materials and Methods}

Inoculum preparation. A single-spore isolate of $F$. virguliforme (LL0009) obtained in 2006 from roots of a symptomatic soybean plant in Nevada, IA was used in all trials of the experiment. The isolate was initially obtained on modified Nash and Snyder medium (MNSM; 5) and then maintained on carnation leaf agar. To prepare inoculum, cultures were grown on potato dextrose agar (PDA; Difco Laboratories, Detroit, MI) for 17 to 19 days at $24 \pm$ $2^{\circ} \mathrm{C}$ in the dark. A conidial suspension was prepared by flooding the cultures with sterilized deionized water (SDW), dislodging the conidia with a rubber policeman, and filtering through three layers of sterile cheese cloth. The conidial concentration was assessed using a hemacytometer and adjusted with SDW to $4 \times 10^{4}$ conidia/ml.

Plant source and growth medium. Soybean 'AG2403' (Asgrow Seed, St. Louis, MO), a glyphosate-tolerant, maturity group II cultivar with an indeterminate growth habit, was used in all trials. Seed were surface disinfected by immersion in $0.5 \%$ sodium hypochlorite for $2 \mathrm{~min}$, followed by rinsing twice in SDW. The plant growth media consisted of a mixture of pasteurized soil and sand $(1: 1, \mathrm{wt} / \mathrm{wt})$ amended with $1.5 \%$ sterilized cornmeal. Soybean plants were grown in rhizotrons to allow repeated observations of the same plants over the course of the experiments. Rhizotrons (0.5-cm thick plexiglass boxes, $24 \mathrm{~cm}$ high by $30 \mathrm{~cm}$ long by 2.5 $\mathrm{cm}$ wide) were divided vertically into two cells, each containing approximately $1 \mathrm{~kg}$ of soil mixture.

Experimental design and conditions. The experiment was established as a split-plot design with soil temperature as the whole-plot factor and plant age at inoculation as the subplot factor. The experimental unit was a rhizotron containing two plants, and 
there were three replicate rhizotrons per each plant age treatment within each main plot. Soil temperature treatments were created using three water baths set at 17,23 , and $29^{\circ} \mathrm{C}\left( \pm 1^{\circ} \mathrm{C}\right)$, respectively. The water baths were $152 \mathrm{~cm}$ long by $91 \mathrm{~cm}$ wide by $30 \mathrm{~cm}$ high, and were located in a greenhouse maintained at $24^{\circ} \mathrm{C}\left( \pm 5^{\circ} \mathrm{C}\right)$. The experiment was repeated once.

Seed for all treatments were planted on the same day at a depth of $1 \mathrm{~cm}$ in each rhizotron cell, appressing the seed to one wall of the rhizotron. Rhizotrons were then wrapped with aluminum foil to maintain roots in the dark and submerged into the water baths at a $30^{\circ}$ angle to promote root growth against the plexiglass surface. Sixteen rhizotrons were placed in each water bath, with four rhizotrons randomly assigned to each of the four plant age treatments. Within each plant age treatment, three replicate rhizotrons were inoculated and one was used as a noninoculated control. Inoculation was conducted $0,3,7$, and 13 days after planting (DAP) on the subset of six plants (two plants in each of the three rhizotrons) assigned to the corresponding plant age treatments, by drenching the soil in each rhizotron cell with $70 \mathrm{ml}$ of conidial suspension prepared as described above. This resulted in an initial concentration of approximately $3 \times 10^{3}$ conidia/g of soil $(18,19,25,28)$. Control plants were drenched with $70 \mathrm{ml}$ of SDW. The 70-ml volume was chosen because it provided uniform wetting of the soil profile in the rhizotron. On the day of inoculation, plant growth stages ranged from nongerminated seed (planted on the same day of the inoculation) to V5, and root length ranged from 0 to $20 \mathrm{~cm}$ (Table 1). Plants were exposed to a 14-h photoperiod using overhead incandescent light (high-pressure sodium, $400 \mathrm{~W}$ ) in the greenhouse, and fertilized 20 and 26 DAP with a $20 \% \mathrm{~N}$, $10 \% \mathrm{P}, 20 \% \mathrm{~K}$ general-purpose fertilizer. The two trials were planted on 14 May 2008 and 16 July 2009. Plants were watered every 2 to 3 days with approximately $70 \mathrm{ml}$ of tap water in order to maintain a moist soil profile in each rhizotron.

Data collection. To determine root growth rate, tap root length was measured every 2 days from planting until the roots of the fastest-growing plants (those incubated at $29^{\circ} \mathrm{C}$ ) reached the bottom of the rhizotron ( $8 \mathrm{DAP})$. Root and foliar disease severity were evaluated every 1 to 3 days until 21 DAP, then every 6 days until 50 DAP. Root rot severity observed through the rhizotron wall was assessed as the percentage of root length showing brown or black discoloration. Foliar severity was estimated as the percentage of total leaf area exhibiting chlorosis or necrosis typical of SDS. Roots were destructively sampled 50 DAP, gently washed with running tap water, rated for root rot severity, and dried at $89^{\circ} \mathrm{C}$ for $24 \mathrm{~h}$ to estimate the root dry weight.

Data analysis. Severity of root rot and foliar symptoms were plotted against days after inoculation. Day of inoculation was considered time zero and assessments conducted up to 36 days after inoculation were considered for each plant age treatment. Area under the disease progress curve (AUDPC) for root and foliar severity was calculated for each plant age and temperature treatment by using the trapezoidal integration method (4). Root length was linearly regressed against time up to 8 DAP (time when roots reach the bottom of the rhizotrons) in all treatments.

Analysis of variance was performed using the PROC MIXED procedure of SAS (SAS Institute, Cary, NC) on the AUDPC, root growth rate (centimeters per day), and root dry weight (grams). Data used in the analysis for each variable were the averages of the two plants in a rhizotron (experimental unit). Data for noninoculated control plants were not included in the analysis because symptoms never developed on roots or leaves in any treatment. The two trials of the experiment were used as the block factor for the

Table 1. Root length and growth stage of soybean plants ('AG2403') inoculated with Fusarium virguliforme 0, 3, 7, and 14 days after planting in rhizotrons and incubated at three soil temperatures

\begin{tabular}{lccrc}
\hline & \multicolumn{4}{c}{ Root length $(\mathbf{c m})$ at each plant age $^{\mathbf{a}}$} \\
\cline { 2 - 5 } Soil temperature $\left({ }^{\circ} \mathbf{C}\right)$ & 0 DAP & 3 DAP & 7 DAP & 13 DAP \\
\hline 17 & 0 (Seed) & $2.9 \pm 0.1(\mathrm{G})$ & $8.8 \pm 0.7(\mathrm{VE})$ & $15.9 \pm 0.6(\mathrm{VE})$ \\
23 & 0 (Seed) & $5.6 \pm 0.5(\mathrm{G})$ & $18.0 \pm 0.2(\mathrm{VC})$ & $19.7 \pm 0.4(\mathrm{~V} 1)$ \\
29 & 0 (Seed) & $8.3 \pm 0.9(\mathrm{VE})$ & $19.4 \pm 0.4(\mathrm{VC})$ & $20.3 \pm 0.4(\mathrm{~V} 1)$ \\
\hline
\end{tabular}

a Plant age at inoculation; DAP = days after planting. Soybean growth stage: Seed = ungerminated seed, $\mathrm{G}=$ germinated seed, $\mathrm{VE}=$ emergence, $\mathrm{VC}=$ cotyledonary leaves, and V1 = first trifoliate leaf.

Table 2. Analysis of variance on the effects of soil temperature and plant age at inoculation on the area under disease progress curve (AUDPC) for root rot and foliar severity of soybean sudden death syndrome on plants ('AG2403') grown in greenhouse conditions

\begin{tabular}{|c|c|c|c|c|c|c|c|}
\hline \multirow[b]{2}{*}{ Source ${ }^{a}$} & \multirow[b]{2}{*}{ df } & \multicolumn{3}{|c|}{ Root rot AUDPC } & \multicolumn{3}{|c|}{ Foliar severity AUDPC } \\
\hline & & MSE & $F$ & $P>F$ & MSE & $F$ & $P>F$ \\
\hline Trial & 1 & 759,306 & 2.7 & 0.2436 & 244,015 & 5.9 & 0.135 \\
\hline Soil temperature (main plot) & 2 & 232,047 & 8.2 & 0.1090 & 104,110 & 2.5 & 0.2840 \\
\hline Main plot error & 2 & 283,879 & 2.8 & 0.0693 & 41,285 & 0.5 & 0.6119 \\
\hline Plant age (subplot) & 3 & $6,455,510$ & 63.6 & $<0.0001$ & $7,221,000$ & 86.6 & $<0.0001$ \\
\hline Soil temperature $\times$ plant age & 6 & 540,130 & 5.3 & 0.0002 & 240,392 & 2.8 & 0.0159 \\
\hline Subplot error & 57 & 101,457 & $\ldots$ & $\ldots$ & $83,322.8$ & $\ldots$ & $\ldots$ \\
\hline
\end{tabular}

${ }^{a}$ Analysis was done by pooling data from the two greenhouse trials.

Table 3. Mean values and standard error of root rot and foliar severity area under disease progress curve (AUDPC) of soybean plants ('AG2403') inoculated with Fusarium virguliforme at four ages and incubated at three soil temperatures

\begin{tabular}{|c|c|c|c|c|c|c|c|c|}
\hline \multirow[b]{2}{*}{ Plant age } & \multicolumn{4}{|c|}{ Root rot AUDPC } & \multicolumn{4}{|c|}{ Foliar severity AUDPC } \\
\hline & $17^{\circ} \mathrm{C}$ & $2^{\circ} \mathrm{C}$ & $29^{\circ} \mathrm{C}$ & $P$ value $^{\mathrm{a}}$ & $17^{\circ} \mathrm{C}$ & $23^{\circ} \mathrm{C}$ & $29^{\circ} \mathrm{C}$ & $P$ value $^{\text {a }}$ \\
\hline 0 & $2,098 \pm 57$ & $2,022 \pm 84$ & $1,980 \pm 79$ & 0.86 & $1,127 \pm 115$ & $1,570 \pm 199$ & $1,407 \pm 282$ & 0.02 \\
\hline 3 & $1,471 \pm 172$ & $1,339 \pm 248$ & $640 \pm 153$ & 0.0008 & $562 \pm 160$ & $237 \pm 83$ & $27 \pm 27$ & 0.0043 \\
\hline 7 & $1,760 \pm 118$ & $929 \pm 190$ & $484 \pm 51$ & $<0.0001$ & $229 \pm 46$ & $49 \pm 26$ & $0.0 \pm 0.0$ & 0.3089 \\
\hline 13 & $635 \pm 121$ & $767 \pm 146$ & $400 \pm 60$ & 0.25 & $0.0 \pm 0.0$ & $0.0 \pm 0.0$ & $0.0 \pm 0.0$ & 1.0 \\
\hline$P$ value ${ }^{\mathrm{b}}$ & $<0.0001$ & $<0.0001$ & $<0.0001$ & $\ldots$ & $<0.0001$ & $<0.0001$ & $<0.0001$ & $\ldots$ \\
\hline
\end{tabular}

\footnotetext{
${ }^{a}$ Statistical significance of mean comparison of AUDPC of a single plant age at inoculation across the three soil temperatures.
}

${ }^{\mathrm{b}}$ Statistical significance of mean comparison of AUDPC among plant age at inoculation at a single soil temperature. 
main plot treatment. Main effects for soil temperature and plant age at inoculation were evaluated using the "slice" option in SAS. The Tukey-Kramer test was used $(\alpha<0.05)$ to test differences in means for AUDPC, root dry weight, and root growth rate. Pearson correlation coefficient and statistical significance were calculated to determine associations among root growth, root rot, and foliar disease.

\section{Results}

Soil temperature and plant age at inoculation affected the development of root rot and foliar symptoms $(P<0.05$; Tables 2 and 3$)$. In general, root rot and foliar symptoms were less severe with increasing soil temperature and with increasing plant age at inoculation. However, plant age and temperature showed a significant interaction (Table 2). At $17^{\circ} \mathrm{C}$, for example, foliar symptoms developed in plants inoculated 0,3 , or 7 DAP, whereas they developed only on plants inoculated 0 and $3 \mathrm{DAP}$ at $29^{\circ} \mathrm{C}$ (Fig. 1). Temperature did not affect root rot AUDPC in plants inoculated at 0 and 13 DAP, whereas those inoculated 3 and 7 DAP showed a significant decrease in root rot AUDPC as temperature increased from 17 to $29^{\circ} \mathrm{C}$ (Table 3). For foliar severity AUDPC, soil temperature significantly impacted plants inoculated at 0 and 3 DAP but not plants inoculated at 7 and $13 \mathrm{DAP}$ at $23^{\circ} \mathrm{C}$ (Table 3 ).

Root growth rate was approximately twice as fast at $29^{\circ} \mathrm{C}$ as at $17^{\circ} \mathrm{C}$ on both inoculated and noninoculated plants (Table 4). Plants inoculated 0 and 3 DAP showed slower root growth rate than noninoculated plants when incubated at 23 and $29^{\circ} \mathrm{C}$. However, root growth rate did not differ among inoculated and noninoculated
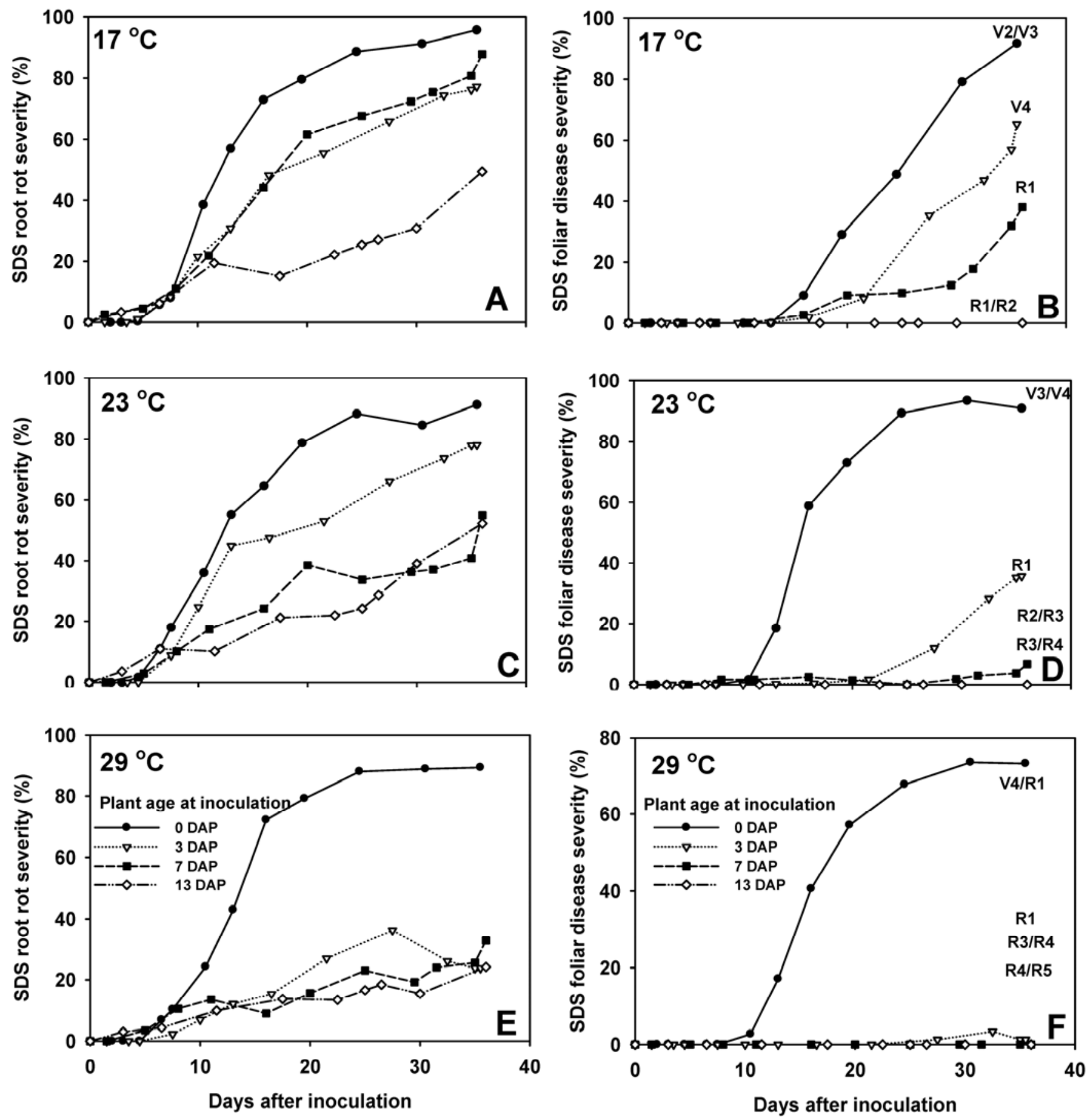

Fig. 1. Progress of root rot and foliar symptoms of soybean sudden death syndrome (SDS) severity on plants ('AG2403') inoculated with Fusarium virguliforme at $0,3,7$, and 13 days after planting (DAP) and incubated at three soil temperatures: $\mathbf{A}$ and $\mathbf{B}, 17^{\circ} \mathrm{C} ; \mathbf{C}$ and $\mathbf{D}, 23^{\circ} \mathbf{C}$; and $\mathbf{E}$ and $\mathbf{F}, 29^{\circ} \mathbf{C}$. Soybean growth stages 36 days after inoculation are shown for each plant age treatment in the foliar severity graphs (values from top to bottom are for plants inoculated $0,3,7$, and 13 DAP, respectively). 
plants incubated at $17^{\circ} \mathrm{C}$ (Table 4). Because root growth was measured only for the first $8 \mathrm{DAP}$, root growth rates for plants inoculated 7 and 13 DAP were pooled with noninoculated plants. Root dry weight increased significantly with increasing soil temperature at all plants ages except 0 DAP, and was significantly lower on plants inoculated 0 DAP than plants inoculated at older ages (Table 4).

Root growth rate was negatively correlated with root rot AUDPC and positively correlated with root dry weight (Table 5). Root length at inoculation was positively correlated with dry weight and negatively correlated with root rot and foliar severity variables. Foliar AUDPC were positively correlated with root rot AUDPC and negatively correlated with root dry weight and root length at inoculation (Table 5).

\section{Discussion}

This study provides evidence that temperature and plant age at inoculation greatly affect root rot and foliar severity of soybean SDS. The duration of the period of susceptibility to infection and subsequent development of SDS foliar symptoms was found to be shorter at warmer temperatures than at cool temperatures. SDS root and foliar symptoms generally became less severe as soil temperature and plant age at inoculation increased; however, there was a significant interaction between these factors. For example, although root rot was less severe at warmer soil temperatures on plants inoculated 3 and 7 DAP, plants inoculated 0 DAP showed similar root rot severity at all temperatures. These results were similar to previous research on Fusarium root rot (16), where no differences in root rot were found when bean plants were inoculated at seed stage and incubated at 18 and $27^{\circ} \mathrm{C}$.

Foliar symptoms also tended to be less severe at warmer soil temperatures but severity was impacted by plant age at inoculation. Plants inoculated at seed stage developed severe foliar symptoms at all temperatures but severity was greatly reduced or absent on older plants grown at the warmer temperatures. This is consistent with previous reports (6) that plants inoculated at seed stage (0 DAP) were more susceptible to SDS than plants inoculated 3 or more DAP. Because root growth was faster at warmer temperatures (12), the findings of this study suggest that susceptibility to SDS is affected by the developmental stage of the roots when they are exposed to the pathogen. A decrease in disease severity with increasing plant maturity has been reported for other soybean root pathogens $(13,30)$

Biochemical mechanisms possibly involved in the greater disease resistance of older plants include the production of phytoalexins, such as glyceollin, as soybean root tissues mature $(13,20)$. In addition, suberin can defend roots against pathogen invasion (30) and can be synthesized in soybean roots within 2 to 4 days after pathogen inoculation (21). Therefore, it is possible that defense mechanisms activated within the timeframe of root growth observed in this study caused a delay in xylem colonization by $F$. virguliforme, subsequently delaying the movement of toxin to the leaves $(11,18)$ and the onset of foliar symptoms on older plants. On plants inoculated 0 DAP, soil temperature did not affect root rot AUDPC because inoculation occurred before the root could be modified (e.g., production of suberin) in response to the different temperatures.

Like other soil physical factors, such as compaction and oxygen content, that affect root development $(2,3,16)$, cool temperatures caused a significant reduction in root growth rate and dry weight in plants inoculated at all ages in this study. Root dry weight can be a useful measure of $F$. virguliforme aggressiveness (14) and has been shown to be correlated with foliar symptoms of SDS in field conditions (24). In this study, root weight was greatest on older plants, particularly at the warmer temperatures. The negative correlation between root growth parameters (growth rate, root dry weight, and root length) and root and foliar AUDPC supports the hypothesis

Table 4. Mean and standard error of root growth rate and root dry weight of soybean plants ('AG2403') inoculated with Fusarium virguliforme at four different ages and incubated at three soil temperatures

\begin{tabular}{|c|c|c|c|c|}
\hline \multirow[b]{2}{*}{ Plant age at inoculation (DAP) ${ }^{a}$} & \multicolumn{3}{|c|}{ Soil temperature $\left({ }^{\circ} \mathbf{C}\right)$} & \multirow[b]{2}{*}{$P$ value ${ }^{b}$} \\
\hline & 17 & 23 & 29 & \\
\hline \multicolumn{5}{|l|}{ Root growth rate $(\mathrm{cm} / \mathrm{day})^{\mathrm{c}}$} \\
\hline 0 & $1.1 \pm 0.11$ & $1.8 \pm 0.13$ & $2.1 \pm 0.09$ & $<0.0001$ \\
\hline 3 & $1.1 \pm 0.11$ & $1.9 \pm 0.12$ & $2.3 \pm 0.11$ & $<0.0001$ \\
\hline Noninoculated plants ${ }^{\mathrm{d}}$ & $1.3 \pm 0.04$ & $2.5 \pm 0.04$ & $2.8 \pm 0.03$ & $<0.0001$ \\
\hline$P$ value & 0.13 & $<0.0001$ & $<0.0001$ & $\ldots$ \\
\hline \multicolumn{5}{|l|}{ Root dry weight $(\mathrm{g})^{\mathrm{f}}$} \\
\hline 0 & $0.04 \pm 0.005$ & $0.06 \pm 0.018$ & $0.13 \pm 0.043$ & 0.557 \\
\hline 3 & $0.15 \pm 0.025$ & $0.29 \pm 0.043$ & $0.85 \pm 0.150$ & $<0.0001$ \\
\hline 7 & $0.18 \pm 0.049$ & $0.50 \pm 0.054$ & $0.82 \pm 0.157$ & $<0.0001$ \\
\hline 13 & $0.35 \pm 0.062$ & $0.51 \pm 0.095$ & $0.90 \pm 0.147$ & $<0.0001$ \\
\hline Noninoculated & $0.28 \pm 0.029$ & $0.54 \pm 0.081$ & $0.68 \pm 0.087$ & $<0.0001$ \\
\hline$P$ value & 0.006 & $<0.0001$ & $<0.0001$ & $\ldots$ \\
\hline
\end{tabular}

${ }^{\mathrm{a}} \mathrm{DAP}=$ days after planting.

${ }^{\mathrm{b}}$ Statistical significance for mean comparison among temperatures within each plant age.

${ }^{\mathrm{c}}$ Root length measurements were done up to 8 DAP; therefore, plants inoculated 7 and 13 DAP were similar to the noninoculated control.

${ }^{\mathrm{d}}$ Mean rate for plants inoculated 7 and 13 DAP and noninoculated control plants.

${ }^{\mathrm{e}}$ Statistical significance for mean comparison among plant ages within each soil temperature.

${ }_{\mathrm{f}}^{\mathrm{f}}$ Dry weight estimation was done by destructively sampling at 50 DAP.

Table 5. Pearson correlation coefficients between area under disease progress curve (AUDPC) for root rot and foliar severity and root growth variables for soybean plants ('AG2403') inoculated with Fusarium virguliforme at four ages and incubated at three soil temperatures ${ }^{\mathrm{a}}$

\begin{tabular}{lccccc}
\hline Disease-associated variables & $\begin{array}{c}\text { Root growth rate } \\
(\mathbf{c m} / \mathbf{d a y})^{\mathbf{b}}\end{array}$ & $\begin{array}{c}\text { Root length at } \\
\text { inoculation } \mathbf{( c m})\end{array}$ & $\begin{array}{c}\text { Root dry weight } \\
(\mathbf{g})\end{array}$ & $\begin{array}{c}\text { Root rot } \\
\text { AUDPC }\end{array}$ & $\begin{array}{c}\text { Foliar severity } \\
\text { AUDPC }\end{array}$ \\
\hline Root growth rate (cm/day) & $\ldots$ & $0.58^{*}$ & $0.77^{* *}$ & $-0.61^{*}$ & $-0.35 \mathrm{~ns}$ \\
Root length at inoculation $(\mathrm{cm})$ & $\ldots$ & $\ldots$ & $0.76^{* *}$ & $-0.85^{* *}$ & $-0.79^{* *}$ \\
Root dry weight $(\mathrm{g})$ & $\ldots$ & $\ldots$ & $\ldots$ & $-0.90^{* *}$ & $-0.73^{* *}$ \\
Root rot AUDPC & $\ldots$ & $\ldots$ & $\ldots$ & $\ldots$ & $0.86^{* *}$ \\
Foliar severity AUDPC & $\ldots$ & $\ldots$ & $\ldots$ & $\ldots$ & $\ldots$ \\
\hline
\end{tabular}

${ }^{a}$ Correlation between growth rate and foliar severity variables was done up to 7 days after planting. Statistical significance: $* *$ and $*$ indicate $P<0.01$ and 0.05 , respectively; $\mathrm{ns}=$ not significant.

${ }^{\mathrm{b}}$ Correlation was done by considering the effect of the three soil temperatures on root traits and disease variables from inoculated plants only $(n=12)$. 
that accelerated root growth in warm soils may be a factor influencing disease severity $(3,17,22)$. Other studies also showed that low soil temperature constrained root growth on bean plants and increased Fusarium root rot $(2,3,16)$. Because all plants were assessed for root weight 50 DAP, the loss of root mass observed in plants inoculated at the younger ages resulted from the longer period of exposure to the pathogen (8).

The lower disease severity observed at warmer soil temperatures in this study is consistent with previous reports that delayed soybean planting reduced SDS severity in field conditions $(9,10)$. Although many factors affect SDS development in the field $(23,27,28)$, including the possibility of new infections later in the growing season (6), the fact that plants inoculated at seed stage developed severe symptoms at all temperatures in this study suggests that soil temperatures at planting may not affect SDS development if other conditions, such as soil moisture and inoculum density, are favorable for infection as soon as seed germinate. Therefore, optimizing seedbed conditions to promote fast root growth may be an important strategy for managing SDS, especially when planting early in fields with a history of the disease. The findings from this study also highlight the need to clarify the role of root growth variables (e.g., growth rate, length, and weight) on susceptibility to SDS, and determine the mechanisms involved in root resistance to infection conducive to foliar symptoms. This knowledge may assist breeders in determining root traits that should be taken into account when developing soybean cultivars with resistance to SDS.

\section{Acknowledgments}

This study was funded by the Iowa Soybean Association and the North Central Soybean Research Program. We thank T. Kaspar, United States Department of Agriculture-Agricultural Research Service National Soil Tilth Laboratory, Ames, IA, for expert advice on root growth and physiology; and P. Dixon, Department of Statistics at Iowa State University, for advice on the statistical analysis.

\section{Literature Cited}

1. Aoki, T., O’Donnell, K., and Scandiani, M. M. 2005. Sudden death syndrome of soybean in South America is caused by four species of Fusarium: Fusarium brasiliense sp. nov., F. cuneirostrum sp. nov., F. tucumaniae, and F. virguliforme. Mycoscience 46:162-183.

2. Burke, D. W. 1968. Root growth obstructions and Fusarium root rot of beans. Phytopathology 58:1575-1576.

3. Burke, D. W., Miller, D. E., and Barker, A. W. 1980. Effects of soil temperature on growth of beans in relation to soil compaction and Fusarium root rot. Phytopathology 70:1047-1049.

4. Campbell, C. L., and Madden, L. V. 1990. Introduction to Plant Disease Epidemiology. John Wiley \& Sons, New York.

5. Cho, J. H., Rupe, J. C., Cummings, M. S., and Gbur, E. E., Jr. 2001. Isolation and identification of Fusarium solani f. sp. glycines from soil on modified Nash and Snyder's medium. Plant Dis. 85:256-260.

6. Gongora-Canul, C. C., and Leandro, L. F. S. 2011. Plant age affects root infection and development of foliar symptoms of soybean sudden death syndrome. Plant Dis. 95:242-247.

7. Gray, L. E., and Achenbach, L. A. 1996. Severity of foliar symptoms and root and crown rot of soybean inoculated with various isolates and inoculum rates of Fusarium solani. Plant Dis. 80:1197-1199.

8. Hart, L. P., and Endo, R. M. 1981. The effect of length of exposure to inoculum, plant age, root development, and root wounding on Fusarium yellows of celery. Phytopathology 71:77-79.

9. Hershman, D. E., Hendrix, J. W., Stuckey, R. E., Bachi, P. R., and Henson, G. 1990. Influence of planting date and cultivar on soybean sudden death syndrome in Kentucky. Plant Dis. 74:761-766.

10. Hirrel, M. C. C. 1986. Disease severity and yield loss comparison of soybean maturity groups affected in sudden death syndrome. (Abstr.). Proc. South. Soybean Dis. Work. 15:61.

11. Jin, H., Hartman, G. L., Nickell, C. D., and Widholm, J. M. 1996. Characterization and purification of a phytotoxin produced by Fusarium solani, the causal agent of soybean sudden death syndrome. Phytopathology 86:277-282.

12. Kuruppu, P. U., Schneider, R. W., and Russin, J. S. 2004. Factors affecting soybean root colonization by Calonectria ilicicola and development of red crown rot following delayed planting. Plant Dis. 88:613-619.

13. Lazarovits, G., Stissel, P., and Ward, E. W. B. 1981. Age-related changes in specificity and glyceollin production in the hypocotyl reaction of soybeans to Phytophthora megasperma var. sojae. Phytopathology 71:94-97.

14. Li, S., Hartman, G. L., and Chen, Y. 2009. Evaluation of aggressiveness of Fusarium virguliforme isolates that cause sudden death syndrome. J. Plant Pathol. 91:77-86.

15. McLean, K. S., and Lawrence, G. W. 1993. Interrelationship of Heterodera glycines and Fusarium solani in sudden death syndrome of soybean. J. Nematol. 25:434-439.

16. Miller, D. E., and Burke, D. W 1985. Effects of low soil oxygen on Fusarium root rot of beans with respect to seedling age and soil temperature. Plant Dis. 69:328-330.

17. Monfort, W. S., Kirkpatrick, T. L., and Rothrock, C. S. 2006. Effects of nocturnal soil temperatures and Meloidogyne incognita densities on cotton seedling growth and the interaction with Thielaviopsis basicola. Plant Dis. 90:519-522.

18. Navi, S. S., and Yang, X. B. 2008. Foliar symptom expression in association with early infection and xylem colonization by Fusarium virguliforme (formerly $F$. solani f. sp. glycines), the causal agent of soybean sudden death syndrome. Plant Health Progress doi:10.1094/PHP-2008-0222-01-RS.

19. Njiti, V. N., Johnson, J. E., Torto, T. A., Gray, L. E., and Lightfoot, D. A. 2001. Inoculum rate influences selection for field resistance to soybean sudden death syndrome in the green house. Crop Sci. 41:1726-1731.

20. Paxton, J. D., and Chamberlain, D. W. 1969. Phytoalexin production incompatible race 4 interactions, in spite of increased resistance and disease resistance in soybeans as affected by age. Phytopathology 59:775-777.

21. Ranathunge, K., Thomas, R. H., Fang, X., Peterson, C. A., Gijzen, M., and Bernards, M. A. 2008. Soybean root suberin and partial resistance to root rot caused by Phytophthora sojae. Phytopathology 98:1179-1189.

22. Rothrock, C., S. 1992. Influence of soil temperature, water and texture on Thielaviopsis basicola and the black root rot of cotton. Phytopathology 82:1202-1206.

23. Roy, K. W., Lawrence, G. W., Hodges, H. H., McLean, K. S., and Killebrew, J. F. 1989. Sudden death syndrome of soybean: Fusarium solani as incitant and relation of Heterodera glycines to disease severity. Phytopathology 79:191-197.

24. Rupe, J. C. 1989. Frequency and pathogenicity of Fusarium solani recovered from soybean with sudden death syndrome. Plant Dis. 73:581-584.

25. Rupe, J. C., Robbins, R. T., and Gbur, E. E., Jr. 1997. Effect of crop rotation on soil population densities of Fusarium solani and Heterodera glycines and on the development of sudden death syndrome of soybean. Crop Prot. 16:575-580.

26. Scherm, H., and Yang, X. B. 1996. Development of sudden death syndrome of soybean in relation to soil temperature and soil water matric potential. Phytopathology 86:642-649.

27. Scherm, H., and Yang, X. B. 1999. Risk assessment for sudden death syndrome of soybean in the north-central United States. Agric. Syst. 59:301310 .

28. Scherm, H., Yang, X. B., and Lundeen, P. 1998. Soil variables associated with sudden death syndrome in soybean fields in Iowa. Plant Dis. 82:11521157

29. Smith, E. F., and Backman, P. A. 1989. Epidemiology of southern stem canker: effect of time of inoculum application on disease severity. Plant Dis 73:464-468.

30. Thomas, R., Fang, X., Ranathunge, K., Anderson, T. R., Peterson, C. A., and Bernards, M. A. 2007. Soybean root suberin: anatomical distribution, chemical composition, and relationship to partial resistance to Phytophthora sojae Plant Physiol. 144:299-311.

31. Walker, N. R., Kirkpatrick, T. L., and Rothrock, C. S. 1999. Effect of temperature on and histopathology of the interaction between Meloidogyne incognita and Thielaviopsis basicola on cotton. Phytopathology 89:613617.

32. Wrather, J. A., Kendig, S. R., Anand, S. C., Niblack, T. L., and Smith, G. S. 1995. Effects of tillage, cultivar, and planting date on percentage of soybean leaves with symptoms of sudden death syndrome. Plant Dis. 79:560-562.

33. Wrather, J. A., and Koenning S. R. 2009. Effects of diseases on soybean yields in the United States 1996 to 2007. Plant Health Progress doi:10.1094/PHP-2009-0401-01-RS. 